\title{
Human rhabdomyosarcoma cells express functional erythropoietin receptor: Potential therapeutic implications
}

\author{
AGATA PONIEWIERSKA-BARAN ${ }^{1,2}$, MALWINA SUSZYNSKA ${ }^{1,2}$, WENYUE SUN $^{3}$, \\ AHMED ABDELBASET-ISMAIL ${ }^{1}$, GABRIELA SCHNEIDER ${ }^{1}$, \\ FREDERIC G. BARR ${ }^{4}$ and MARIUSZ Z. RATAJCZAK ${ }^{1,3}$

\begin{abstract}
${ }^{1}$ Stem Cell Institute at James Graham Brown Cancer Center, University of Louisville, Louisville, KY, USA; ${ }^{2}$ Department of Physiology, Pomeranian Medical University in Szczecin, Szczecin; ${ }^{3}$ Department of Regenerative Medicine, Warsaw Medical University, Warsaw, Poland; ${ }^{4}$ Laboratory of Pathology, National Cancer Institute, Bethesda, MD, USA
\end{abstract}

Received July 7, 2015; Accepted August 19, 2015

DOI: 10.3892/ijo.2015.3184

\begin{abstract}
The erythropoietin receptor (EpoR) is expressed by cells from the erythroid lineage; however, evidence has accumulated that it is also expressed by some solid tumors. This is an important observation, because recombinant erythropoietin (EPO) is employed in cancer patients to treat anemia related to chemo/radiotherapy. In our studies we employed eight rhabdomyosarcoma (RMS) cell lines (three alveolar-type RMS cell lines and five embrional-type RMS cell lines), and mRNA samples obtained from positive, PAX7-FOXO1-positive, and fusion-negative RMS patient samples. Expression of EpoR was evaluated by RT-PCR, gene array and FACS. The functionality of EpoR in RMS cell lines was evaluated by chemotaxis, adhesion, and direct cell proliferation assays. In some of the experiments, RMS cells were exposed to vincristine (VCR) in the presence or absence of EPO to test whether EPO may impair the therapeutic effect of VCR. We report for a first time that functional EpoR is expressed in human RMS cell lines as well as by primary tumors from RMS patients. Furthermore, EpoR is detectably expressed in both embryonal and alveolar RMS subtypes. At the functional level, several human RMS cell lines responded to EPO stimulation by enhanced proliferation, chemotaxis, cell adhesion, and phosphorylation of MAPKp42/44 and AKT. Moreover, RMS cells became more resistant to VCR treatment in the presence of EPO. Our findings have important potential clinical implications, indicating that EPO supplementation in RMS patients may have the unwanted side effect of tumor progression.
\end{abstract}

Correspondence to: Professor Mariusz Z. Ratajczak, Stem Cell Institute at James Graham Brown Cancer Center, University of Louisville, 500 S. Floyd Street, Room 107, Louisville, KY 40202, USA

E-mail: mzrata01@louisville.edu

Key words: rhabdomyosarcoma, erythropoietin, erythropoietin receptor, metastasis

\section{Introduction}

Rhabdomyosarcoma (RMS) is the most common soft-tissue sarcoma of adolescence and childhood. RMS accounts for 5\% of all malignant tumors in patients under 15 years of age $(1,2)$ and belongs to the family of so-called 'small round blue tumor cells', which often infiltrate bone marrow (BM) and can resemble hematological blasts. Thus, RMS cells on BM smears may sometimes be misdiagnosed as acute leukemia cells (2). There are two major histological subtypes of this tumor: alveolar rhabdomyosarcoma (ARMS) and embryonal rhabdomyosarcoma (ERMS). ARMS is associated with more aggressive behavior and a worse prognosis than ERMS.

At the molecular level, ARMS is characterized by the $t(2 ; 13)(q 35 ; q 14)$ translocation in $70 \%$ of cases and the variant $\mathrm{t}(1 ; 13)(\mathrm{p} 36 ; \mathrm{q} 14)$ in a smaller percentage of cases (3). These translocations disrupt the PAX3 and PAX7 genes on chromosomes 2 and 1, respectively, and the $F O X O 1$ gene on chromosome 13, generating PAX3-FOXO1 and PAX7-FOXOI fusion genes. The resulting fusion proteins, PAX3-FOXO1 and PAX7-FOXO1, have enhanced transcriptional activity compared with wild-type PAX3 and PAX7 and are postulated to play a role in cell survival and dysregulation of the cell cycle in ARMS (1). Recently, we also found that imprinting of the differentially methylated region (DMR) at the DLK1-GTL2 locus varies with the histologic subtype: ERMS tumors have loss of imprinting, whereas ARMS tumors have erasure of imprinting at this locus (4). This difference provides further evidence that the cellular origin of these tumors is different.

The erythropoietin receptor (EpoR) is expressed by cells from the erythroid lineage, although evidence has accumulated that it is also expressed by several solid tumors (5-13) including neuroblastoma, Ewing's sarcoma family of tumors, pediatric brain tumors (medulloblastoma, astrocytoma and ependymoma), Wilms' tumor, hepatoblastoma, as well as it had been detected in ERMS but not in ARMS patient cells (14).

Recently our group demonstrated the presence of functional EpoR in human and murine germline-derived cell lines, including teratocarcinomas and ovarian cancer cells (15). This observation is intriguing in the context of the present study, as RMS cells express several cancer testis antigens (CTAs) (16), 
which are characteristic of germline-derived cells. Moreover, 150 years ago, Virchow (17) and Conheim (18) proposed the so-called 'embryonic rest hypothesis of cancer development', in which malignancies may develop from dormant embryonic or germ cells residing in adult tissues. Small round blue cell tumors, including RMS, are potential candidates for such malignancies. Interestingly, a recent study demonstrated that the $P A X 7$ gene, which plays an important role in skeletal muscle development, is one of the stem cell markers in gonads (19). However, the potential relationship between the germline and target cells for RMS requires further study.

In the present study, we found expression of EpoR mRNA in all tested RMS cell lines and patient samples. Importantly, EpoR was functional in all RMS cell lines tested, responding to stimulation by erythropoietin (EPO) by an increase in chemotaxis, adhesion, and phosphorylation of MAPKp42/44 and AKT. Moreover, EPO stimulates proliferation of RMS cells and may also increase their resistance to vincristine (VCR). Our results have important clinical implications for potential EPO therapy in cancer patients to ameliorate tumor-associated anemia. The presence of functional EpoR in RMS cells indicates that EPO supplementation may have the unwanted side effect of facilitating tumor progression in RMS patients.

\section{Materials and methods}

Cell lines. We used several human RMS cell lines (provided by Dr Peter Houghton, Nationwide Children's Cancer Center, Columbus, OH, USA), including both fusion-positive (RH28, RH30 and RH41) and fusion-negative (JR, RD, RH18, RH36 and SMS-CTR) cell lines. All cell lines used in these studies were authenticated by short tandem repeat (STR) analysis. STR profiles were compared with those of the original cell lines, obtained in Dr Peter Houghton's laboratory, or with published profiles. SMS-CTR and RH36 cells were cultured in Dulbecco's modified Eagle's medium (DMEM) containing $10 \%$ fetal bovine serum (FBS), $100 \mathrm{U} / \mathrm{ml}$ penicillin and $10 \mu \mathrm{g} / \mathrm{ml}$ streptomycin. All other cell lines were maintained in Roswell Park Memorial Institute (RPMI)-1640 medium, containing $10 \%$ FBS, $100 \mathrm{U} / \mathrm{ml}$ penicillin and $10 \mu \mathrm{g} / \mathrm{ml}$ streptomycin. All cells were cultured in a humidified atmosphere of $5 \% \mathrm{CO}_{2}$ at $37^{\circ} \mathrm{C}$, and the medium was changed every $48 \mathrm{~h}$.

Quantitative reverse transcription ( $q R T)$ - PCR to detect EpoR $m R N A$. Total RNA was isolated from RMS cells with the RNeasy kit (Qiagen, Inc., Valencia, CA, USA). Human muscle RNA was obtained from Ambion (Austin, TX, USA). The RNA was reverse-transcribed with MultiScribe Reverse Transcriptase, oligo(dT) and a random hexamer primer mix (all from Applied Biosystems Life Technologies, Foster City, CA, USA). Quantitative assessment of the mRNA levels of target genes was performed by qRT-PCR using an ABI Prism 7500 sequence detection system (Applied Biosystems Life Technologies) with Power SYBR-Green PCR Master mix reagent and specific primers $(h E p o R$ forward, CCA TGG ACA CTG TGC CCT G and reverse, CCA TCG GAT AAG CCC CCT T; $h E P O$ forward, CAC CAC GCC TCA TCT GTG AC and reverse, CAC AGC CCG TCG TGA TAT TCT). The PCR cycling conditions were as follows: $95^{\circ} \mathrm{C}(15 \mathrm{sec}), 40$ cycles at $95^{\circ} \mathrm{C}(15 \mathrm{sec})$ and $60^{\circ} \mathrm{C}(1 \mathrm{~min})$. According to melting point analysis, only one PCR product was amplified under these conditions. The relative quantity of a target, normalized to the endogenous $\beta 2$-microglobulin gene as control and relative to a calibrator, is expressed as $2^{-\Delta \Delta C t}$ (fold difference), where $\mathrm{Ct}$ is the threshold cycle, $\Delta \mathrm{Ct}=(\mathrm{Ct}$ of target genes) $-(\mathrm{Ct}$ of the endogenous control gene, $\beta 2$-microglobulin $)$, and $\Delta \Delta \mathrm{Ct}=(\Delta \mathrm{Ct}$ for target gene in test sample)-( $\Delta \mathrm{Ct}$ for target gene in calibrator sample).

Conventional RT-PCR. Total RNA from various cells was isolated using the RNeasy Mini kit, including treatment with DNase I (both from Qiagen, Inc.). The mRNA (200 ng) was reverse-transcribed with TaqMan Reverse Transcription Reagents (Applied Biosystems Life Technologies) according to the manufacturer's instructions. The resulting cDNA fragments were amplified ( 1 cycle of $8 \mathrm{~min}$ at $95^{\circ} \mathrm{C}, 2$ cycles of $2 \mathrm{~min}$ at $95^{\circ} \mathrm{C}, 1 \mathrm{~min}$ at $60^{\circ} \mathrm{C}, 1 \mathrm{~min}$ at $72^{\circ} \mathrm{C}$, and subsequently 35 cycles of $30 \mathrm{sec}$ at $95^{\circ} \mathrm{C}, 1 \mathrm{~min}$ at $60^{\circ} \mathrm{C}, 1 \mathrm{~min}$ at $72^{\circ} \mathrm{C}$, and 1 cycle of $10 \mathrm{~min}$ at $72^{\circ} \mathrm{C}$ ) using AmpliTaq Gold with sequence-specific primers designed using the NCBI/Primer-BLAST program; one primer was designed to include an exon-intron boundary $(\beta$-actin forward, GGA TGC AGA AGG AGA TCA CTG and reverse, CGA TCC ACA CGG AGT ACT TG; $h E p o R$ forward, CTC CCT TTG TCT CCT GCT CG and reverse, TAG GCA GCG AAC ACC AGA AG; $h E P O$ forward, TCA TCT GTG ACA GCC GAG TC and reverse, GCC ACT GAC GGC TTT ATC CA; and $h C D 131$ forward, AGG GGC AGA AGA AAC CAT CC and reverse, GGC CTG TCT GGT TGG AAT GA).

Cell proliferation. Cells were grown in 24-well culture plates at an initial density of $1.5 \times 10^{4}$ cells/well. After $24 \mathrm{~h}$, the medium was changed to new medium supplemented with $10 \%$ FBS, and the cells were cultured in the presence or absence of VCR ( $1 \mathrm{nM}$ to $1 \mu \mathrm{M}$ ). The complete medium (with $10 \%$ FBS) was used as a control. The cell number was calculated at 24,48 and $72 \mathrm{~h}$ after the change of medium. At the indicated time points, cells were harvested from the culture plates by trypsinization.

Chemotaxis assay. Chemotaxis assays were performed in a modified Boyden's chamber with 8- $\mu \mathrm{m}$ pore polycarbonate membrane inserts (Costar Transwell; Corning Costar, Lowell, MA, USA) as previously described (20). In brief, cells detached with $0.25 \%$ trypsin were seeded into the upper chamber of an insert at a density of $4.5 \times 10^{4}$ in $100 \mu$ l. The lower chamber was filled with pre-warmed culture medium containing test reagents. Medium supplemented with $0.5 \%$ BSA was used as a negative control. After $24 \mathrm{~h}$, the inserts were removed from the Transwell supports. The cells that had not migrated were scraped off with cotton wool from the upper membrane, and the cells that had transmigrated to the lower side of the membrane were fixed and stained with HEMA 3 (protocol; Thermo Fisher Scientific, Pittsburgh, PA, USA) and counted on the lower side of the membrane using an inverted microscope.

Hypoxia assay. A hypoxic condition was achieved by using a nitrogen-balanced hypoxia chamber (BioSpherix Ltd., Lacona, $\mathrm{NY}$, USA) providing a gas mixture containing $5 \% \mathrm{CO}_{2}$ and $2 \%$ $\mathrm{O}_{2}$ at $37^{\circ} \mathrm{C}$. 
Phosphorylation of intracellular pathway proteins. RMS cell lines were incubated overnight in RPMI-1640 medium containing low levels of bovine serum albumin (BSA, $0.5 \%$ ) to render the cells quiescent. After the cells were stimulated with $\mathrm{EPO}(0.5$ and $20 \mathrm{IU} / \mathrm{ml})$ at $37^{\circ} \mathrm{C}$ for $5 \mathrm{~min}$, the cells were lysed for 10 min on ice in RIPA lysis buffer containing protease and phosphatase inhibitors (Santa Cruz Biotechnology, Inc., Santa Cruz, CA, USA). The extracted proteins were separated on a 4-12\% SDS-PAGE gel and transferred to a PVDF membrane. Phosphorylation of the serine/threonine kinase AKT (phospho-AKT473) and p44/42 mitogen-activated kinase (phospho-p44/42 MAPK) was detected by phospho-specific p44/42 MAPK mouse and rabbit polyclonal antibodies (Cell Signaling Technology, Inc., Danvers, MA, USA) with HRP-conjugated goat anti-mouse and anti-rabbit secondary antibodies (Santa Cruz Biotechnology, Inc.). Equal loading in the lanes was evaluated by stripping the blots and reprobing with anti-p42/44 MAPK monoclonal antibody (clone no. 9102) and anti-AKT polyclonal antibody (both from Cell Signaling Technology, Inc.). The membranes were developed with an enhanced chemiluminescence (ECL) reagent (Amersham Life Sciences, Arlington Heights, IL, USA), dried, and subsequently exposed to film (Hyperfilm; Amersham Life Sciences).

Adhesion assay to fibronectin. Cells were made quiescent for $3 \mathrm{~h}$ with $0.5 \%$ BSA in RPMI-1640 before incubation with EPO ( 2 and $20 \mathrm{IU} / \mathrm{ml})$. Subsequently, cell suspensions $\left(2 \times 10^{3} / 100 \mu \mathrm{l}\right)$ were added directly to 96 -well plates covered with fibronectin and incubated for $5 \mathrm{~min}$ at $37^{\circ} \mathrm{C}$. The wells were coated with fibronectin $(10 \mu \mathrm{g} / \mathrm{ml})$ overnight at $4^{\circ} \mathrm{C}$ and blocked with $0.5 \%$ BSA for $1 \mathrm{~h}$ before the experiment. Following incubation, the plates were vigorously washed three times to remove non-adherent cells, and the adherent cells were counted using an inverted microscope.

Hypoxic assay. To evaluate the effect of hypoxia on expression of CD131 and endogenous EPO and EpoR in RMS cells, cells were incubated in hypoxic condition by using a nitrogen-balanced hypoxia chamber providing a gas mixture containing $5 \% \mathrm{CO}_{2}$ and $2 \% \mathrm{O}_{2}$ at $37^{\circ} \mathrm{C}$. Cells were treated for $24 \mathrm{~h}$ and subsequently RNA has been extracted for RT-PCR analysis using RNeasy kit (Qiagen, Inc.).

FACS analysis. To evaluate expression of EpoR in fusion positive and negative RMS cells, the cells were incubated with human EpoR antibody (APC, clone 38421) for $30 \mathrm{~min}$ on ice. After washing, cells were evaluated using a BD LSR II flow cytometer (BD Biosciences, San Jose, CA, USA). Representative FACS results are shown. FACS analysis was also employed in proliferation assay in the presence of VCR $(1 \mathrm{nM}-1 \mu \mathrm{M})$ or EPO $(20 \mathrm{IU} / \mathrm{ml})$ and in apoptosis assay employing Annexin V-PE.

Apoptosis assay. RMS cells were cultured with or without EPO (20 IU/ml) and with or without VCR $(1 \mu \mathrm{M})$ in serum-free medium for 24, 48 and $72 \mathrm{~h}$. Apoptosis was detected by FACS using the Annexin V-PE Apoptosis Detection kit (BD Pharmingen, San Diego, CA, USA). Cells were stained for apoptotic cell detection with Annexin V-PE for 15 min at RT.
Patient samples. Fifty-eight RMS frozen primary tumor specimens (26 PAX3-FOXO1-positive, 7 PAX7-FOXO1-positive, and 25 fusion-negative) were used for microarray profiling. Total RNA was extracted from primary tumors using RNA STAT-60 (Tel-Test, Friendswood, TX, USA) in accordance with manufacturer's instructions. These RNA samples were analyzed on Affymetrix GeneChip ${ }^{\circledR}$ Human Genome U133 Plus 2.0 Arrays at the University of Pennsylvania Microarray Core Facility. The expression array data were normalized and $\log 2$ transformed with Robus Multiarray Average (RMA) in the Bioconductor oligo package. The expression level of EPOR was calculated as an average of three probe sets (probe set ID: 215054_at, 209962_at and 37986_at). Probe set ID 215059_at is the only available probe set for CD131 on the U133 Plus 2.0 array.

Statistical analysis. The results are presented as mean $\pm \mathrm{SD}$. Statistical analysis of the data was done using Student's t-test for unpaired samples, with $\mathrm{P}<0.05$ considered significant.

\section{Results}

Human RMS cell lines express EpoR. First, we performed RT-PCR studies to evaluate mRNA expression in three human fusion-positive (RH28, RH30 and RH41) as well as five human fusion-negative (JR, RD, RH18, RH36 and SMS-CTR) RMS cell lines. Fig. 1A, shows that we were able to detect EpoR mRNA by regular RT-PCR in all cell lines employed in this study, but not in skeletal muscle cells. As shown in Fig. 1B, all cell lines, especially RH18 and RH36, expressed high levels of EpoR mRNA as determined by quantitative RT-PCR. Of note very week signal was also detected in skeletal muscle cells by employing this highly sensitive cDNA amplification method. Expression of EpoR was subsequently confirmed by FACS (Fig. 1C), and RH36 and RH18 highly expressed this receptor at the protein level. No expression was detected on skeletal muscle cells (data not shown).

Since it is known that EPO signals via EpoR-EpoR homodimers in erythroid cells and may signal via EpoR-CD131 heterodimers in non-erythroid cells $(21,22)$, we evaluated the expression of CD131 in our RMS cell lines by FACS and RT-PCR, and found that CD131 was not detectably expressed in these cells (data not shown). However, when we exposed RMS cells to hypoxia, CD133 become detectable (Fig. 2A). In parallel we observed upregulation of EpoR and EpO (Fig. 2B). Furthermore, since our RT-PCR analysis revealed expression of endogenous EpO in studied RMS cell lines (Fig. 3), we cannot exclude contribution of autocrine EpO-EpoR interactions, and this phenomenon is currently investigated in our laboratory.

EpoR induces motility and adhesion of cells in human RMS cell lines. Next, to evaluate whether EpoR is functional in human RMS cell lines, we performed chemotaxis and cell adhesion studies. In Transwell chemotaxis assays (Fig. 4A) we employed EPO at doses of 5, 20 and $50 \mathrm{U} / \mathrm{ml}$ as chemoattractant and compared the responsiveness of RMS cells to $300 \mathrm{ng} / \mathrm{ml}$ of the $\alpha$-chemokine stromal-derived factor 1 (SDF-1), which, as we previously described $(23,24)$, is a known chemoattractant for these cells. We observed that 
A
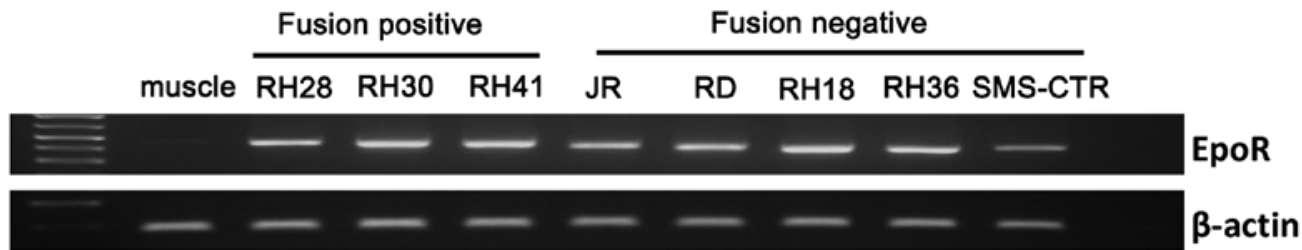

B
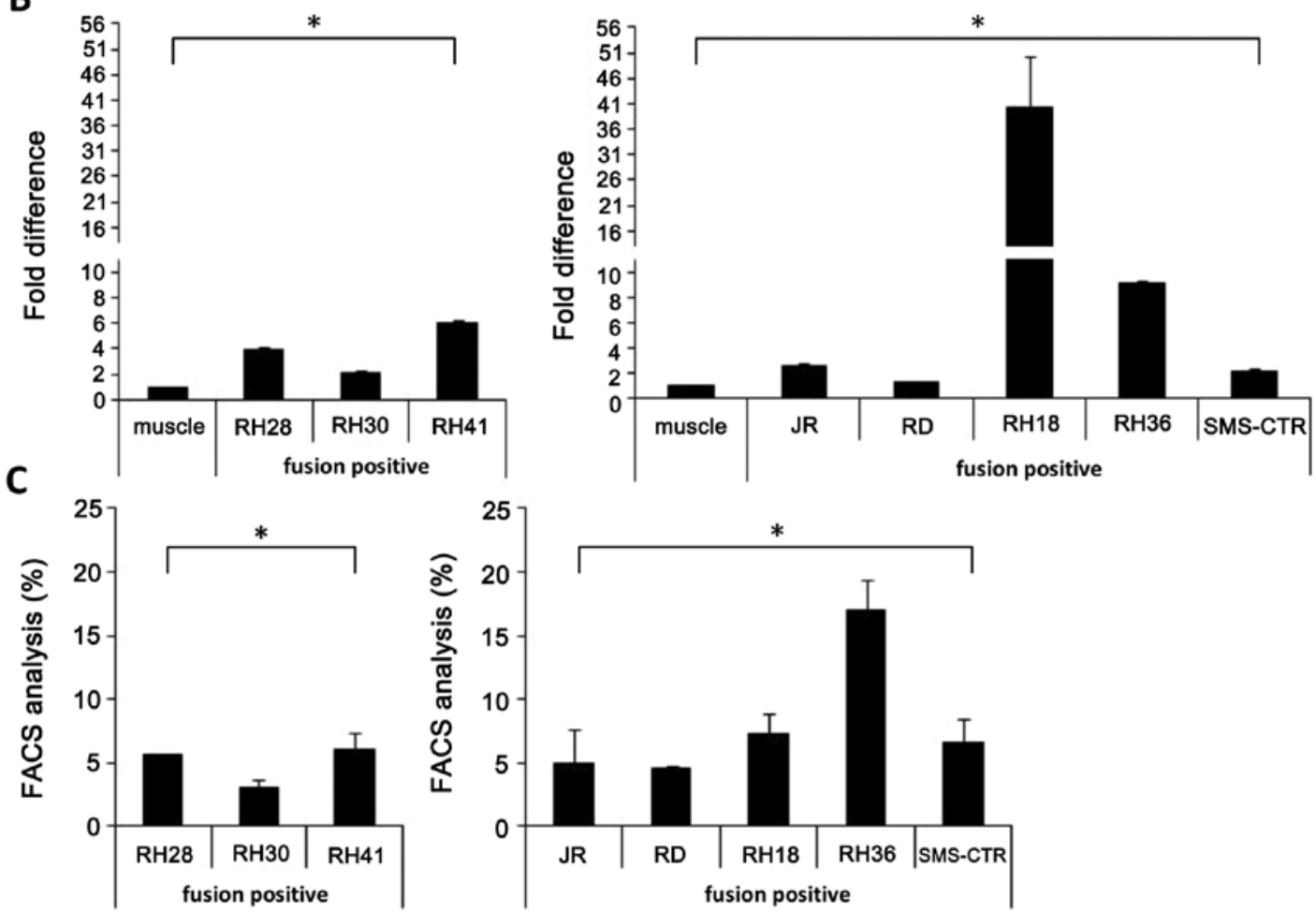

Figure 1. EpoR is expressed in human rhabdomyosarcoma (RMS) cell lines. (A) Expression of EpoR at the mRNA level by RH28, RH30, and RH41 fusionpositive RMS cells and JR, RD, RH18, RH36, and SMS-CTR fusion-negative RMS cells was assessed by RT-PCR. Representative results are shown. (B) Quantitative RT-PCR analysis of EpoR mRNA expression in normal skeletal muscle (positive control) and RMS cell lines. Representative results are shown. (C) FACS analysis of EpoR expression in human RMS cell lines. Combined data from two independent experiments are shown. $\mathrm{P}<0.05$.

A
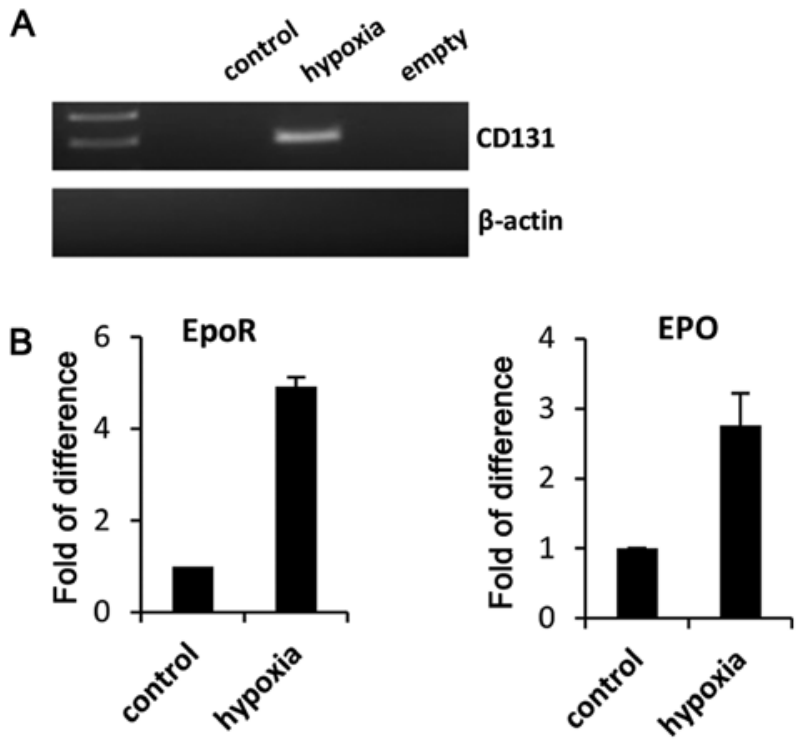

Figure 2. Hypoxia upregulates expression of Epo, EpoR and CD131. (A) Hypoxia upregulates CD131 expression in RMS cells. RH36 rhabdomyosarcoma (RMS) cells were exposed for $24 \mathrm{~h}$ to hypoxia. Empty is $\mathrm{H}_{2} \mathrm{O}$ instead of cDNA. (B) Quantitative (qRT)-PCR analysis of EpoR (left) and endogenous EPO (right) in RH36 RMS cells under normoxic and hypoxic conditions.
EPO induced motility of all RMS cell lines evaluated in our studies. The highest responsiveness was observed for RH30 (fusion-positive) cell lines and for RH18, RH30, RH36 and RH28 cell lines. The specificity of EpO-EpoR interaction has been confirmed by employing EpoR blocking antibodies (data not shown).

The motility of cancer cells plays a crucial role in the process of tumor metastasis, and to address whether the observed increase in motility of RMS cells in response to EPO is the result of a chemotactic or a chemokinetic response, we performed a checkerboard assay in which EPO was added at the same time into the upper and the lower Transwell chambers so that there was no EPO gradient between the chambers. Fig. 4B, demonstrates that the migration of RH30 cells in response to EPO in the upper and lower chambers was not significantly changed when it was in both chambers compared to only one, the lower chamber. This finding indicates that EPO is mainly a chemokinetic rather than a chemotactic factor for RMS cells.

Another important feature of metastasizing cancer cells is their adhesive properties at the site of metastasis. Therefore, we next studied the effect of EPO on adhesion of RMS cell lines to fibronectin. Depending on the dose employed, 


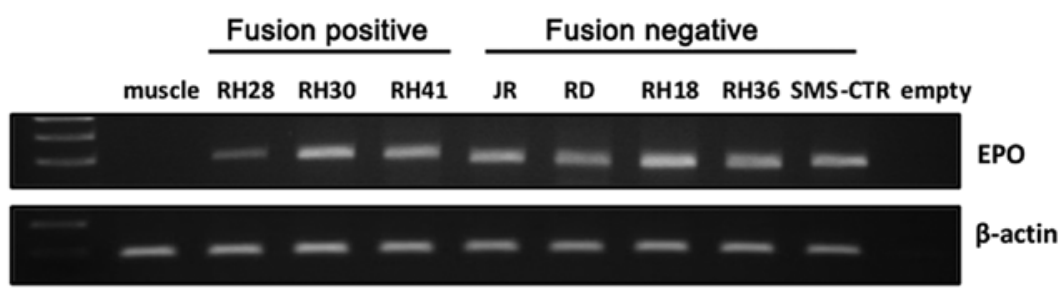

Figure 3. Endogenous EPO level in fusion positive and negative RMS cells. Representative data of RT-PCR analysis for EPO expression is shown. Empty sample - $\mathrm{H}_{2} \mathrm{O}$ instead of cDNA.
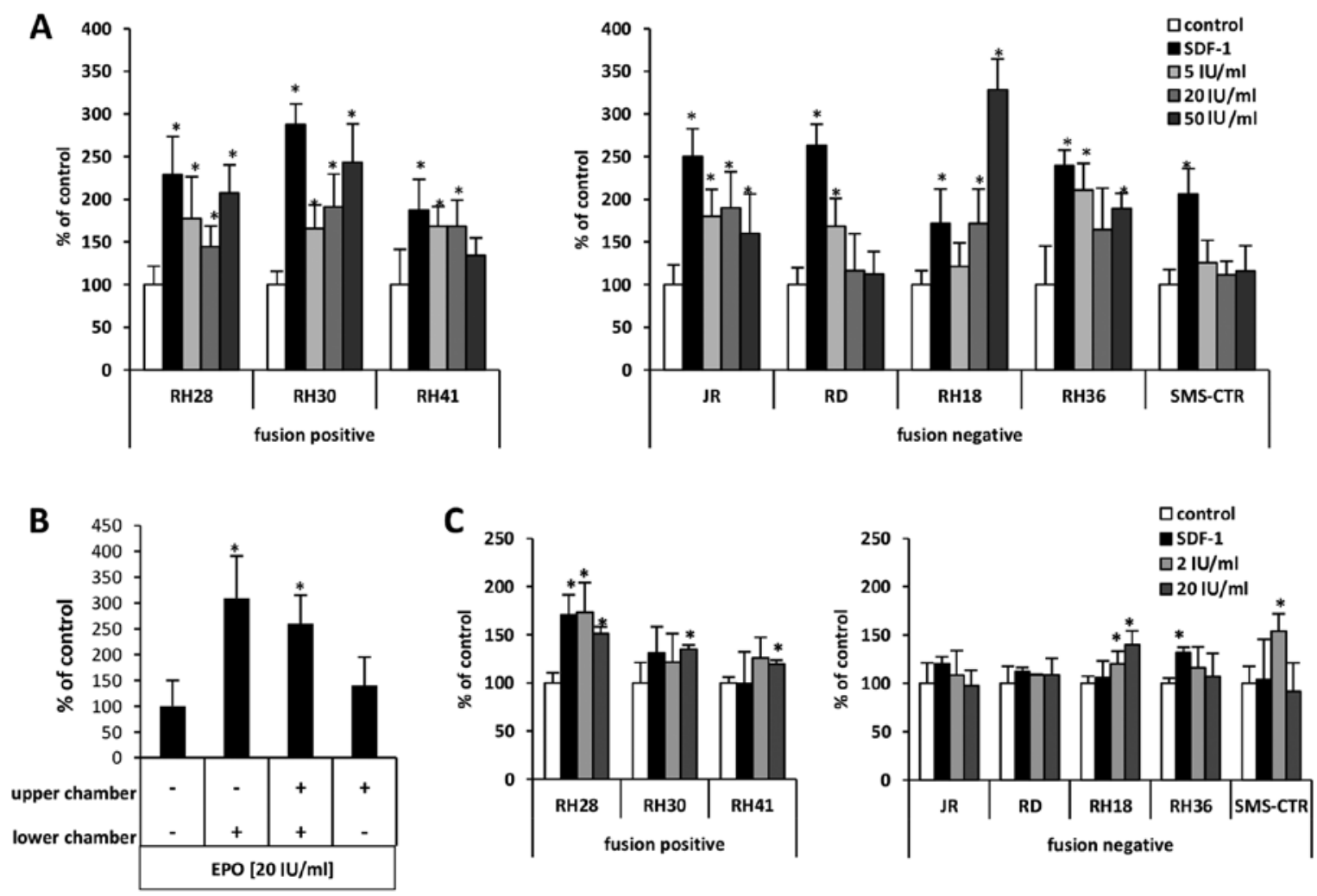

Figure 4. Erythropoietin (EPO) enhances migration and adhesion of human RMS cell lines. (A) Effect of EPO (5, 20 or 50 IU/ml) on the chemoattraction of fusion-positive and fusion-negative cells across Transwell membranes covered with gelatin. SDF-1 $(300 \mathrm{ng} / \mathrm{ml})$ was used as positive control. Combined data from three independent experiments are shown. (B) Checkerboard assay in which EPO was added at the same time into the upper and lower Transwell chambers to prevent gradient formation between the chambers. Combined data from three independent experiments are shown. (C) Effect of EPO (2 or $20 \mathrm{IU} / \mathrm{ml}$ ) on adhesion of RMS cells to fibronectin. Combined data from three independent experiments are shown. $\mathrm{P}<0.05$.

we found that EPO may induce adhesion of RMS cells to fibronectin (Fig. 4C), and this effect was particularly visible for RH28 and SMS-CTR cells. Again, the specificity of EpO-EpoR interaction was confirmed by employing EpoR blocking antibodies (data not shown).

EPO may induce proliferation of RMS cells and increase their resistance to $V C R$. EPO is a known growth factor for erythroid cells (22) as well as for some tumor cell lines (5-14). Therefore, based on receptor expression studies (Fig. 1), we exposed RH18 cell line and the RH36 cell line to $20 \mathrm{IU} / \mathrm{ml}$ EPO and evaluated its effect on proliferation of these cells. We found that EPO stimulated proliferation of both RH18 (Fig. 5A) and RH36 cells (Fig. 5B). Western blot analysis confirmed that both cell lines responded to EPO stimulation by phosphorylation of $\mathrm{MAPK}^{\mathrm{p} 44 / 42}$ and to a lesser degree also by phosphorylation of $\mathrm{Akt}^{\mathrm{ser} 473}$.
Since EPO has pro-proliferative effects on RMS cells, to assess its effect on the potential resistance of RMS cells to chemotherapy, we performed proliferation assays of these cells in medium supplemented with EPO and different doses of VCR. As demonstrated in Fig. 6, we observed an increase in survival of RH18 (Fig. 6A) and RH36 cells (Fig. 6B) in the presence of VCR (25). While a significant beneficial effect was observed for RH18 cells after and $72 \mathrm{~h}$ of treatment, some beneficial effect for RH36 cells was observed after only $24 \mathrm{~h}$ of treatment. The cell proliferation data are supported by the effect of EpO on inhibiting apoptosis in VCR treated cells (data not shown).

EpoR is expressed in patient RMS samples. Finally, we assessed EpoR expression from expression microarray analyses of 26 PAX3-FOXO1-positive, 7 PAX7-FOXO1-positive, and 25 fusion-negative patient samples. In all these tumor 

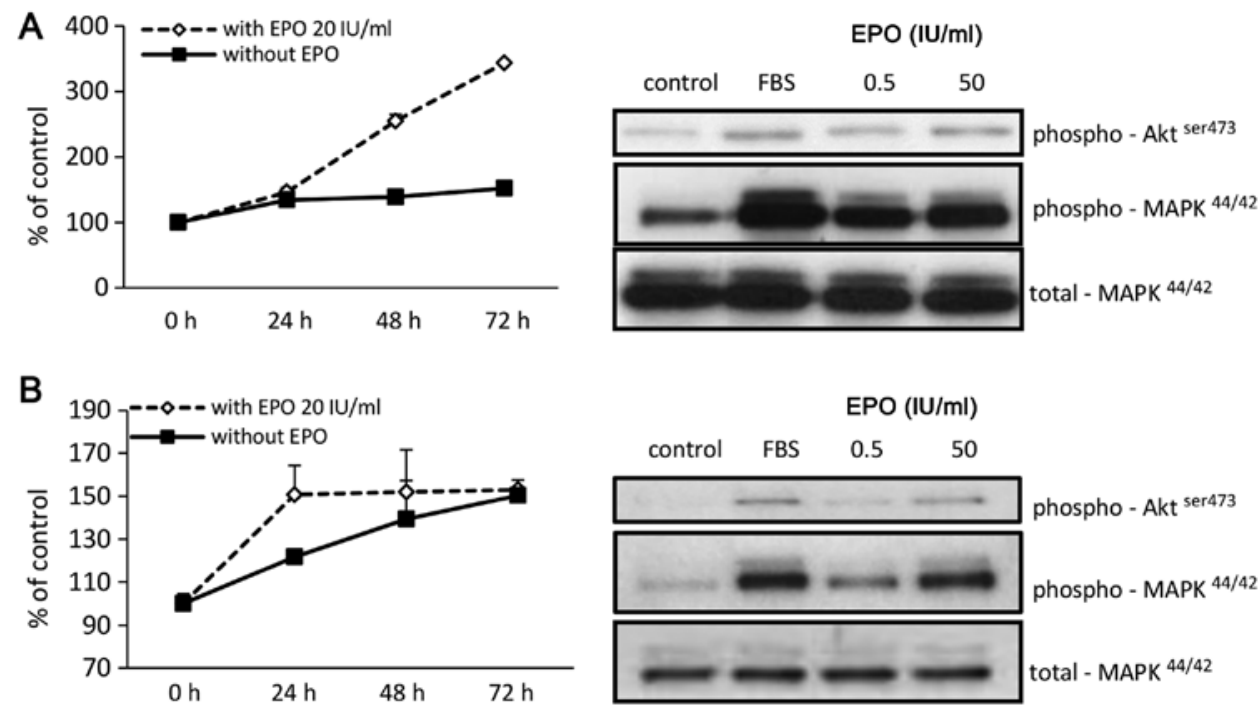

Figure 5. Effect of EPO on proliferation and activation of MAPK ${ }^{\mathrm{p} 42 / 44}$ and AKT in human RMS cells. (A) Effect of EPO on proliferation of the RH18 cell line (left panel) and activation of MAPK ${ }^{\mathrm{p} 42 / 44}$ and AKT (right panel). Representative western blot analysis of both proteins is shown. (B) Effect of EPO on proliferation of the RH36 cell line (left panel) and activation of MAPK ${ }^{\mathrm{p} 2 / 44}$ and AKT (right panel). Representative western blot analysis of both proteins is shown.

A
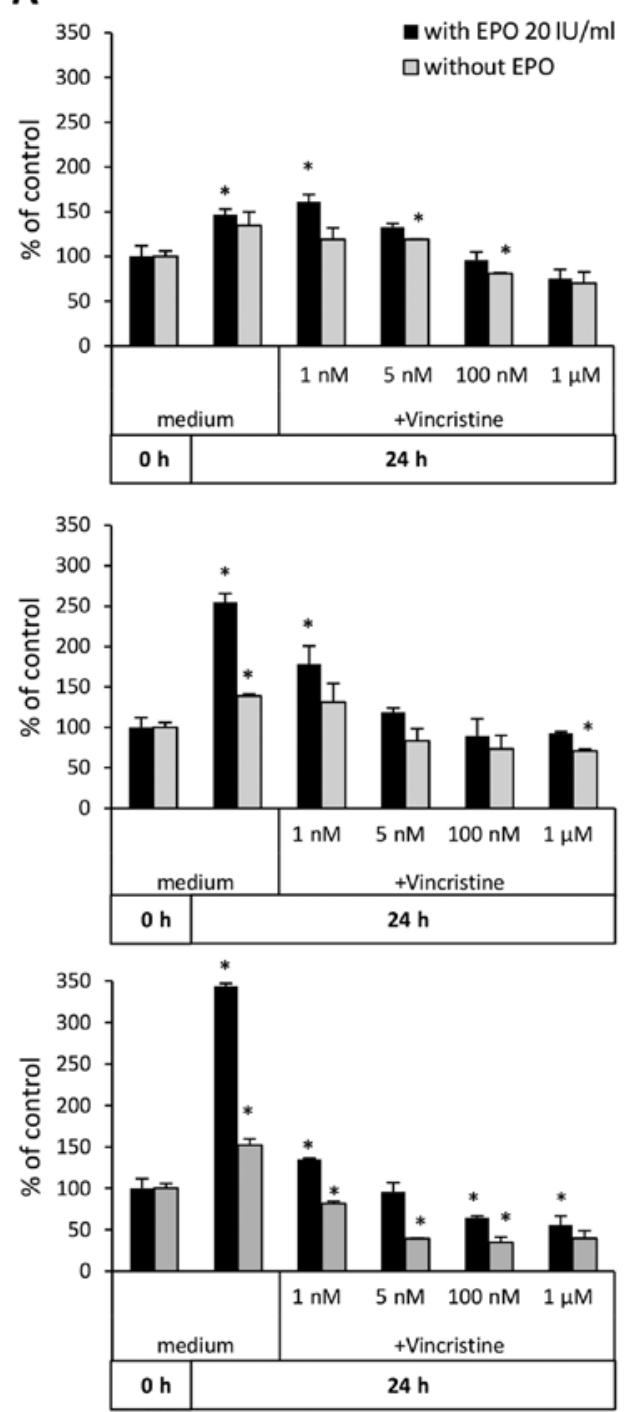

B
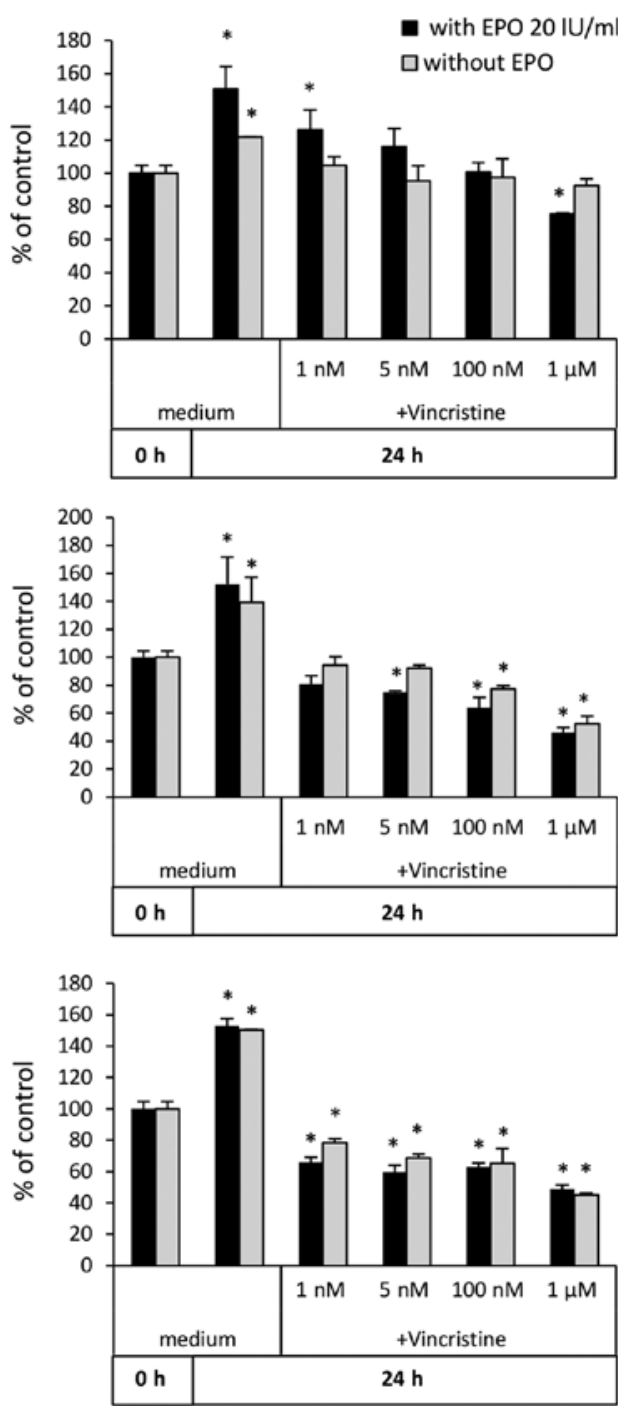

Figure 6. EPO decreased the toxic effects of vincristine (VCR) on RMS cells. Effect of EPO on proliferation of RH18 (A) and RH36 (B) RMS cells in the presence of increasing doses of VCR $(1 \mathrm{nM}$ to $1 \mu \mathrm{M})$. Cells were cultured for 24,48 or $72 \mathrm{~h}\left(37^{\circ} \mathrm{C}, 5 \% \mathrm{CO}_{2}\right)$. Data from three independent experiments are combined. $\mathrm{P}<0.05$. 
A

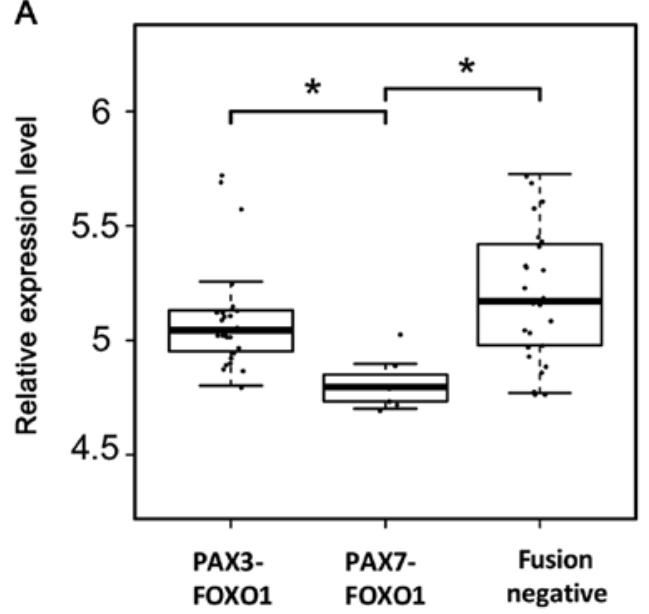

B

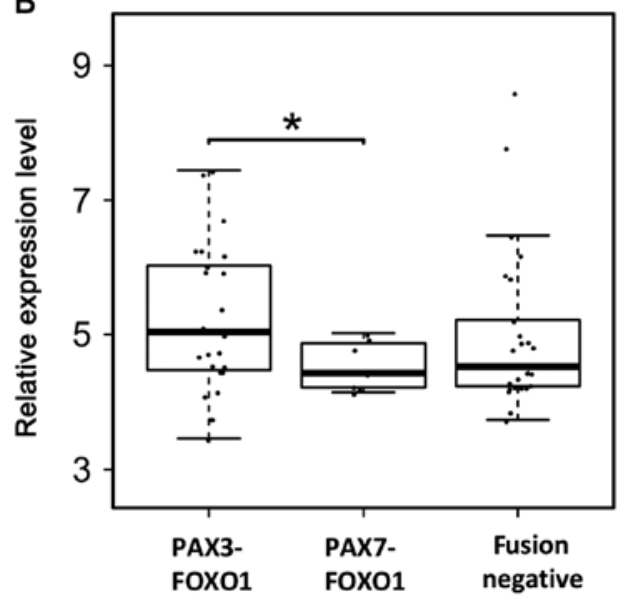

Figure 7. EpoR and CD131 mRNA expression in RMS tumors. Expression levels of EPOR (A) and CD131 (B) were quantified by microarray in PAX3-FOXO1positive, PAX7-FOXO1-positive, and fusion-negative RMS samples. These values were then normalized and log2 transformed as described in Methods and materials. Boxes represent the interquartile range (25-75th percentile) and horizontal lines inside the boxes indicate median. Whiskers indicate the minimum and maximum values, except for outliers. $\mathrm{P}$-value was calculated by using a Student's t-test. $\mathrm{P}<0.05$ was considered significant.

samples, we were able to detect EpoR expression; however, expression of EpoR was higher in PAX3-FOXO1-positive and in fusion-negative samples than in PAX7-FOXO1-positive samples (Fig. 7A). Interestingly, in contrast to established RMS cell lines (data not shown), CD131 expression was detected in all human RMS samples (Fig. 7B), and similar to our EpoR findings, expression of CD133 was higher in PAX3-FOXO1-positive as compared to PAX7-FOXO1positive tumor samples.

\section{Discussion}

It is well-known that systemic anemia is an independent prognostic factor for poor survival in cancer patients (26). Therefore, it has been proposed that recombinant human EPO be used in clinical settings to treat this complication. Unfortunately, such treatment has often resulted in rapid tumor progression and reduced survival (26). EpoR has been reported to be expressed by several solid tumors (5-13) including several pediatric malignancies such as neuroblastoma, Ewing's sarcoma, Wilms' tumor, hepatoblastoma and what is relevant to this study was also detected in ERMS patient tumor samples (14). The salient observation of our work is that not only human ERMS cells (14), but all types of RMS express EpoR and that this receptor may regulate pro-metastatic behavior of RMS cells. Therefore EPO is a previously unrecognized pro-metastatic and growth-promoting factor for this tumor, which indicates a potential risk in treating RMS patient anemia with human recombinant EPO.

EpoR is expressed in cell lines derived from several malignancies; however, to our surprise, no studies on its expression and the role of the EPO-EpoR axis have been performed in RMS cell lines and patient samples. By contrast, it has been shown that EpoR is a negative prognostic factor in gastric, renal, breast, and head and neck cancer and in melanoma $(8-11,26)$. For example, in breast cancer cells EPO stimulates proliferation by involving Egr1 and Fos transcription factors (7), activates the survival of stem-like breast cancer cells to protect them from chemotherapy (6), and antagonizes trastuzumab treatment of breast cancer cells via Jak-2-mediated activation of Src and PTEN inactivation (5). In agreement with these observations, EPO in our hands enhanced the resistance of human RMS cells to VCR treatment.

In some malignancies it has been shown that EPO can be upregulated in a hypoxia-dependent manner and influence tumor cell growth by involving an EPO-EpoR autocrine loop. In support of this mechanism, autocrine-paracrine EPO-EpoR signaling has been described in cervical cancer cells (12). In these tumor cells, EPO, in cooperation with the stem cell factor (SCF), induces migration of malignant cells (13). An autocrine EPO-EpoR axis has also been reported to be involved in the progression of neuroblastoma (27-29). In contrast to our data with RMS cells, EPO did not directly affect cell proliferation in this pediatric cancer (29), but was involved in increasing vascularity of the growing tumor and thus contributed indirectly to its progression $(27,28)$.

Thus, accumulating evidence indicates that EpoR is functional in cells in several human malignancies. It has also been reported that, in contrast to erythroid cells in which EPO signals via EpoR-EpoR homodimers, in nonerythroid cells EPO may signal by employing EpoR-CD131 heterodimers (22). CD131 is known as a the common $\beta$ chain of the high affinity receptor for interleukin-3 (IL-3), interleukin-5 (IL-5) and granulocyte-macrophage colony stimulating factor (GM-CSF) (22). Based on these findings, we evaluated the expression of CD131 in established human RMS cell lines by FACS, but the expression of CD131 was not detected. However, when RMS cells were cultured in hypoxic conditions CD133 as well as EpoR became upregulated, as expected. In contrast CD131 was expressed in RMS patient samples isolated from hypoxic tumor tissue. The role of CD133 that is a common receptor subunit to several receptors for hematopoietic cytokines (GM-CSF, IL-3 and IL-5) in signaling within RMS cells requires further studies.

The recurrence of tumor growth after successful initial treatment and the fatal tendency of cancerous cells to spread 
and metastasize to different vital organs are major problems affecting the survival of cancer patients. The ability to metastasize is one characteristic of highly malignant and primitive tumors, including RMS. The tropism of cancer cells to metastasize to selected organs requires the involvement of organ-specific factors that direct metastasis. These factors may promote the formation of a pre-metastatic niche that provides metastasizing tumor cells with a favorable growth and survival environment.

Here, for the first time, we identified EPO as a potential pro-metastatic factor for RMS cells. The metastasis of RMS cells, however, is directed by several other factors, including growth factors (e.g., hepatocyte growth factor, insulin-like growth factors 1 and 2) (24), chemokines (stromal-derived factor $1 \alpha$ and macrophage inhibitory factor) $(30,31)$, cytokines (leukemia inhibitory factor) (32), as well as several bioactive lipids, such as sphingosine-1-phosphate, ceramide-1-phosphate-1 (33), lysophosphatidylcholine and lysophosphatidic acid (34). In our studies we have shown for the first time that EPO increases the chemokinesis of RMS cells, and thus it may promote their egress from the primary tumor and direct their spread to distant locations.

It is known that the EpoR is expressed by cells from the erythroid lineage and is expressed at very early stages of embryogenesis. Interestingly, we recently demonstrated the presence of functional EpoR in human and murine germline-derived cell lines, including teratocarcinomas and ovarian cancer cells (15). RMS cells also express several CTAs, which are characteristic of germline-derived cells. Interestingly, 150 years ago, Virchow (17) and Conheim (18) proposed the so-called 'embryonic rest hypothesis of cancer development', in which malignancies may develop from dormant embryonic or germ cells residing in adult tissues. Small round blue cell tumors, including RMS, are candidates for such malignancies. In support of this possibility, the $P A X 7$ gene, which plays an important role in skeletal muscle development and is involved in one of the characteristic gene fusions in RMS, has recently been established as a novel marker for gonadal stem cells in testes (19).

In conclusion, since recombinant human EPO is frequently employed to ameliorate chemotherapy-related anemia in cancer patients, our in vitro data have important clinical implications. The presence of functional EpoR in RMS cells indicates that EPO supplementation may have, in the same way as in other malignancies (27), the unwanted side effect of tumor progression. Finally, the presence of functional EpoR in RMS cells and germline-derived tumors as well as expression of CTA antigens by these cells is consistent with the hypothesis that some pediatric sarcomas may develop in adult tissues from embryonic remnants that are endowed with germline characteristics.

\section{Acknowledgements}

The present study was supported by NIH grants (nos. 2R01 DK074720 and R01HL112788), the Stella and Henry Endowment, and the Maestro grant 2011/02/A/NZ4/00035 awarded to M.-Z.R. Work by F.-G.B. and W.S. was supported by the Intramural Research Program of the National Cancer Institute.

\section{References}

1. Collins MH, Zhao H, Womer RB and Barr FG: Proliferative and apoptotic differences between alveolar rhabdomyosarcoma subtypes: A comparative study of tumors containing PAX3-FKHR or PAX7-FKHR gene fusions. Med Pediatr Oncol 37: 83-89, 2001

2. Sandberg AA, Stone JF, Czarnecki L and Cohen JD: Hematologic masquerade of rhabdomyosarcoma. Am J Hematol 68: 51-57, 2001.

3. Davis RJ, D'Cruz CM, Lovell MA, Biegel JA and Barr FG: Fusion of PAX7 to FKHR by the variant $\mathrm{t}(1 ; 13)(\mathrm{p} 36 ; \mathrm{q} 14)$ translocation in alveolar rhabdomyosarcoma. Cancer Res 54: 2869-2872, 1994.

4. Schneider G, Bowser MJ, Shin DM, Barr FG and Ratajczak MZ: The paternally imprinted DLK1-GTL2 locus is differentially methylated in embryonal and alveolar rhabdomyosarcomas. Int J Oncol 44: 295-300, 2014.

5. Liang K, Esteva FJ, Albarracin C, Stemke-Hale K, Lu Y, Bianchini G, Yang CY, Li Y, Li X, Chen CT, et al: Recombinant human erythropoietin antagonizes trastuzumab treatment of breast cancer cells via Jak2-mediated Src activation and PTEN inactivation. Cancer Cell 18: 423-435, 2010.

6. Todaro M, Turdo A, Bartucci M, Iovino F, Dattilo R, Biffoni M, Stassi G, Federici G, De Maria R and Zeuner A: Erythropoietin activates cell survival pathways in breast cancer stem-like cells to protect them from chemotherapy. Cancer Res 73: 6393-6400, 2013.

7. Trost N, Stepisnik T, Berne S, Pucer A, Petan T, Komel R and Debeljak N: Recombinant human erythropoietin alters gene expression and stimulates proliferation of MCF-7 breast cancer cells. Radiol Oncol 47: 382-389, 2013.

8. Morais C, Johnson DW, Vesey DA and Gobe GC: Functional significance of erythropoietin in renal cell carcinoma. BMC Cancer 13: 14, 2013.

9. Seibold ND, Schild SE, Gebhard MP, Noack F, Schröder U and Rades D: Prognosis of patients with locally advanced squamous cell carcinoma of the head and neck. Impact of tumor cell expression of EPO and EPO-R. Strahlenther Onkol 189: 559-565, 2013.

10. Wang L, Li HG, Xia ZS, Wen JM and Lv J: Prognostic significance of erythropoietin and erythropoietin receptor in gastric adenocarcinoma. World J Gastroenterol 17: 3933-3940, 2011.

11. Kumar SM, Zhang G, Bastian BC, Arcasoy MO, Karande P, Pushparajan A, Acs G and Xu X: Erythropoietin receptor contributes to melanoma cell survival in vivo. Oncogene 31: 1649-1660, 2012.

12. Lopez TV, Lappin TR, Maxwell P, Shi Z, Lopez-Marure R, Aguilar C and Rocha-Zavaleta L: Autocrine/paracrine erythropoietin signalling promotes JAK/STAT-dependent proliferation of human cervical cancer cells. Int J Cancer 129: 2566-2576, 2011.

13. Aguilar C, Aguilar C, Lopez-Marure R, Jiménez-Sánchez A and Rocha-Zavaleta L: Co-stimulation with stem cell factor and erythropoietin enhances migration of c-Kit expressing cervical cancer cells through the sustained activation of ERK1/2. Mol Med Rep 9: 1895-1902, 2014.

14. Batra S, Perelman N, Luck LR, Shimada H and Malik P: Pediatric tumor cells express erythropoietin and a functional erythropoietin receptor that promotes angiogenesis and tumor cell survival. Lab Invest 83: 1477-1487, 2003.

15. Suszynska M, Poniewierska-Baran A, Gunjal P, Ratajczak J, Marycz K, Kakar SS, Kucia M and Ratajczak MZ: Expression of the erythropoietin receptor by germline-derived cells - further support for a potential developmental link between the germline and hematopoiesis. J Ovarian Res 7: 66, 2014.

16. Jacobs JF, Brasseur F, Hulsbergen-van de Kaa CA, van de Rakt MW, Figdor CG, Adema GJ, Hoogerbrugge PM, Coulie PG and de Vries IJ: Cancer-germline gene expression in pediatric solid tumors using quantitative real-time PCR. Int J Cancer 120: 67-74, 2007.

17. Virchow R: Archiv fuer pathologische anatomie und physiologie und fuer klinische. Medizin 8: 23-54, 1855 (In German).

18. Conheim J: Congenitales, quergestreiftes Muskelsarkon der Nireren. Virchows Arch 65: 64-69, 1875 (In German).

19. Aloisio GM, Nakada Y, Saatcioglu HD, Peña CG, Baker MD, Tarnawa ED, Mukherjee J, Manjunath H, Bugde A, Sengupta AL, et al: PAX7 expression defines germline stem cells in the adult testis. J Clin Invest 124: 3929-3944, 2014. 
20. Grymula K, Tarnowski M, Wysoczynski M, Drukala J, Barr FG Ratajczak J, Kucia M and Ratajczak MZ: Overlapping and distinct role of CXCR7-SDF-1/ITAC and CXCR4-SDF-1 axes in regulating metastatic behavior of human rhabdomyosarcomas. Int J Cancer 127: 2554-2568, 2010.

21. Rölfing JH, Baatrup A, Stiehler M, Jensen J, Lysdahl H and Bünger C: The osteogenic effect of erythropoietin on human mesenchymal stromal cells is dose-dependent and involves non-hematopoietic receptors and multiple intracellular signaling pathways. Stem Cell Rev 10: 69-78, 2014.

22. Broxmeyer HE: Erythropoietin: Multiple targets, actions, and modifying influences for biological and clinical consideration. J Exp Med 210: 205-208, 2013.

23. Libura J, Drukala J, Majka M, Tomescu O, Navenot JM, Kucia M, Marquez L, Peiper SC, Barr FG, Janowska-Wieczorek A, et al: CXCR4-SDF-1 signaling is active in rhabdomyosarcoma cells and regulates locomotion, chemotaxis, and adhesion. Blood 100: 2597-2606, 2002.

24. Jankowski K, Kucia M, Wysoczynski M, Reca R, Zhao D, Trzyna E, Trent J, Peiper S, Zembala M, Ratajczak J, et al: Both hepatocyte growth factor (HGF) and stromal-derived factor-1 regulate the metastatic behavior of human rhabdomyosarcoma cells, but only HGF enhances their resistance to radiochemotherapy. Cancer Res 63: 7926-7935, 2003.

25. Kang MH, Smith MA, Morton CL, Keshelava N, Houghton PJ and Reynolds CP: National Cancer Institute pediatric preclinical testing program: Model description for in vitro cytotoxicity testing. Pediatr Blood Cancer 56: 239-249, 2011.

26. Maxwell P, Melendez-Rodríguez F, Matchett KB, Aragones J, Ben-Califa N, Jaekel H, Hengst L, Lindner H, Bernardini A, Brockmeier U, et al: Novel antibodies directed against the human erythropoietin receptor: Creating a basis for clinical implementation. Br J Haematol 168: 429-442, 2015.

27. Stolze I, Berchner-Pfannschmidt U, Freitag P, Wotzlaw C, Rössler J, Frede S, Acker H and Fandrey J: Hypoxia-inducible erythropoietin gene expression in human neuroblastoma cells. Blood 100: 2623-2628, 2002.
28. Ribatti D, Poliani PL, Longo V, Mangieri D, Nico B and Vacca A: Erythropoietin/erythropoietin receptor system is involved in angiogenesis in human neuroblastoma. Histopathology 50: 636-641, 2007.

29. Sartelet H, Fabre M, Castaing M, Bosq J, Racu I, Lagonotte E, Scott V, Lecluse Y, Barette S, Michiels S, et al: Expression of erythropoietin and its receptor in neuroblastomas. Cancer 110: 1096-1106, 2007.

30. Tarnowski M, Grymula K, Reca R, Jankowski K, Maksym R, Tarnowska J, Przybylski G, Barr FG, Kucia M and Ratajczak MZ: Regulation of expression of stromal-derived factor-1 receptors: CXCR4 and CXCR7 in human rhabdomyosarcomas. Mol Cancer Res 8: 1-14, 2010.

31. Tarnowski M, Grymula K, Liu R, Tarnowska J, Drukala J, Ratajczak J, Mitchell RA, Ratajczak MZ and Kucia M: Macrophage migration inhibitory factor is secreted by rhabdomyosarcoma cells, modulates tumor metastasis by binding to CXCR4 and CXCR7 receptors and inhibits recruitment of cancer-associated fibroblasts. Mol Cancer Res 8: 1328-1343, 2010.

32. Wysoczynski M, Miekus K, Jankowski K, Wanzeck J, Bertolone S, Janowska-Wieczorek A, Ratajczak J and Ratajczak MZ: Leukemia inhibitory factor: A newly identified metastatic factor in rhabdomyosarcomas. Cancer Res 67: 2131-2140, 2007.

33. Schneider G, Bryndza E, Abdel-Latif A, Ratajczak J, Maj M, Tarnowski M, Klyachkin YM, Houghton P, Morris AJ, Vater A, et al: Bioactive lipids S1P and C1P are prometastatic factors in human rhabdomyosarcoma, and their tissue levels increase in response to radio/chemotherapy. Mol Cancer Res 11: 793-807, 2013.

34. Schneider G, Sellers ZP, Abdel-Latif A, Morris AJ and Ratajczak MZ: Bioactive lipids, LPC and LPA, are novel prometastatic factors and their tissue levels increase in response to radio/chemotherapy. Mol Cancer Res 12: 1560-1573, 2014. 